- says, researchers "have no idea about the mechanism, and they need the mechanism to get new drug targets". Infecting model organs could allow researchers to watch how gene expression and metabolism change in real time.

This sort of information could also be used to identify an unknown agent during a chemical, biological or radiological attack, by providing baseline data on known agents for comparison. John Wikswo, a physiologist at Vanderbilt University in Nashville, Tennessee, and his colleagues have shown that they can rapidly distinguish poisons such as ricin and botulinum toxin by analysing the metabolic activity of cells (S. E. Eklund et al. Sensors 9, 2117-2133; 2009), and will now apply the model-organs approach.

Researchers have already developed dozens of individual model organs; the next challenge is to hook them together with the eventual goal of forming an entire human body on a chip, says Kristin Fabre, a programme manager at the National Center for Advancing Translational Sciences (NCATS) in Bethesda, Maryland. This would provide a more accurate picture of the effects of a drug, toxin or other agent on human physiology.

Wikswo humorously dubs such a system Homo chippiens - but warns that simulating a human body will not be easy. Among other challenges, the blood substitute that flows between model organs must reach them in the right order and in the right quantity, and carry the right nutrients for each organ.

But plenty of people are trying. An NCATS-funded project aims to hook together at least 4 chips; 11 research teams are participating. The US Department of Defense's Defense Advanced Research Projects Agency is supporting the development of techniques to link ten organs, and its Defense Threat Reduction Agency aims to build two four-organ systems.

Fabre predicts that some of the systems could be available to academics and industry within five years. She is hopeful that they will prove especially useful in cases in which animals are poor models for human physiology. As researchers inch closer to that goal, she says, "it's like sci-fi comes to life every day".

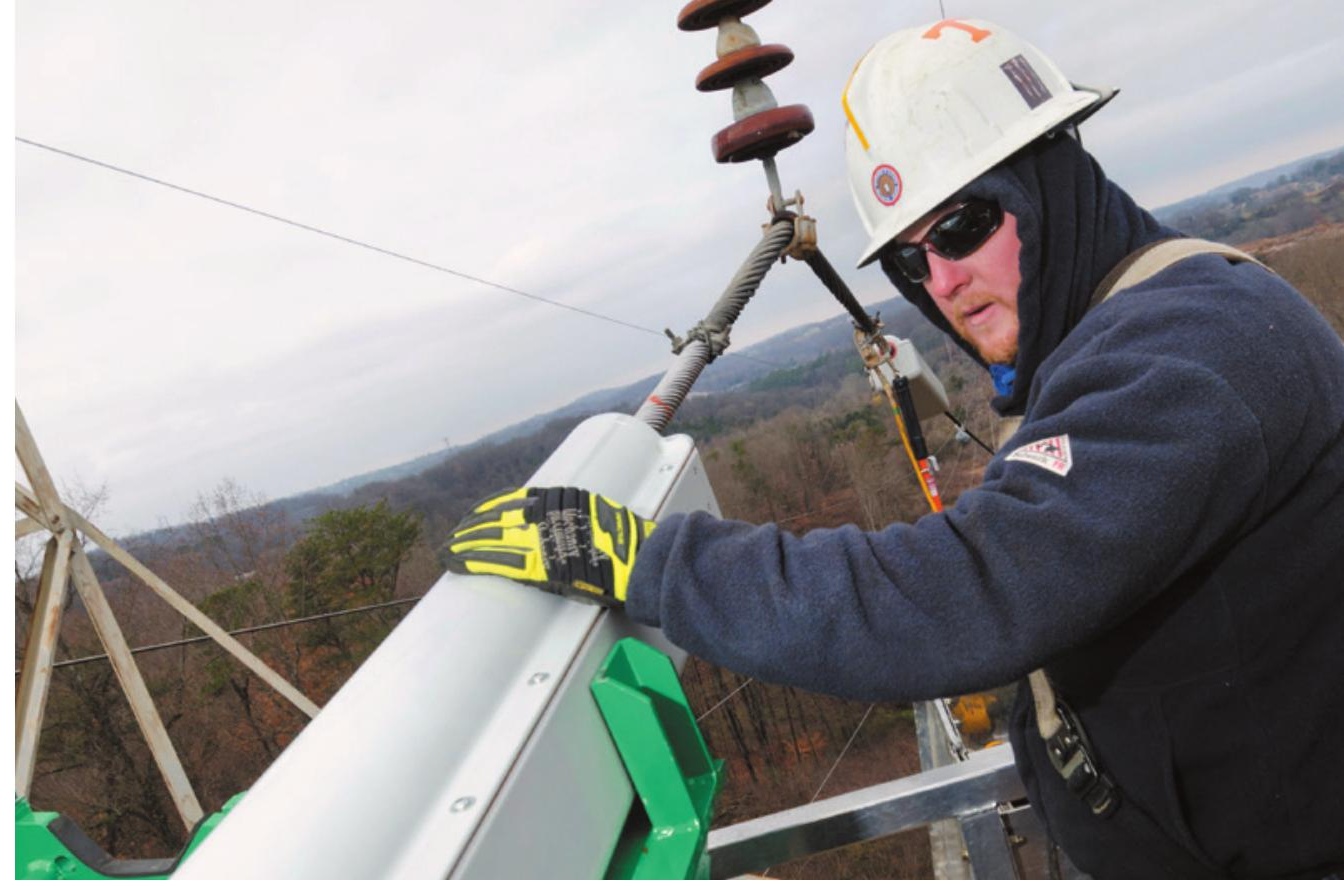

An ARPA-E-funded technology to control power flow is being used by US utility companies.

TECHNOLOGY

\title{
Radical energy ideas secure private funds
}

\author{
US federal start-up funds inspire investment in \\ ARPA-Etechnologies.
}

\section{BY JEFF TOLLEFSON}

A $s$ it enters its seventh year, an ambitious US Department of Energy effort to trigger innovation in clean-energy technology is celebrating some success. At the start of the annual summit of the Advanced Research Projects Agency-Energy (ARPA-E) on 9 February, the programme's management announced that ARPA-E-supported technologies have attracted US $\$ 850$ million in private investment.

At the same time, however, the market for new ideas in energy is not booming, and the mood at the summit was more sedate than in earlier years, when sessions swarmed with investors looking for the next big thing. Most observers of energy innovation counsel patience: even useful ideas often take decades to reach broad application. The US defence department's Defense Advanced Research Projects Agency (DARPA) was the model for ARPA-E, and its biggest success story - the is Internet - took decades to be recognized.

"If we look in 20 or 30 years and can't see an impact, then we can say we have failed," says Ilan Gur, a former ARPA-E programme director who now heads a programme to advance technological innovation at Lawrence Berkeley National Laboratory in Berkeley, California. "The real contribution that ARPA-E has had is in laying out the challenges and bringing together the communities that can solve them."

General enthusiasm for nudging new technologies to market has shrunk since ARPA-E was founded. Venture-capital investments in the United States have dropped off sharply in the past two years; funding for early-stage

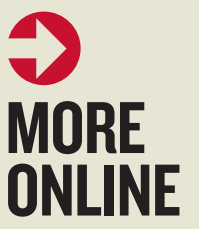

\section{TOP NEWS}

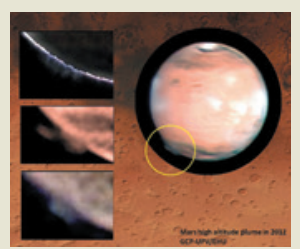

Mysterious Martian plume flummoxes scientists go.nature. com/ars6fw

\section{MORE NEWS}

- Jupiter tests exoplanet technique go.nature.com/gmtj3y - United States to have worst drought in 1,000 years go.nature.com/eszx2a - Forensic scientist builds bridges to lawyers go.nature.com/b9cxp8

\section{Q\&A}

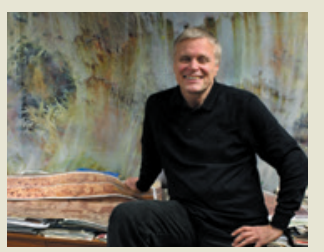

Braving ISIS to do science in the Sahara go.nature. com/gblsza 
clean-energy research has almost disappeared. The administration of US President Barack Obama is seeking to reverse that trend with an initiative, announced on 10 February, to increase private investment. As part of this, the University of California Board of Regents has committed to invest $\$ 1$ billion of its endowment and pension in climate-friendly technologies. The White House also plans to hold a cleanenergy investment summit in coming months.

In its six years, ARPA-E has invested around $\$ 1.1$ billion in 400 projects, ranging from large-scale electricity storage to modern grid technologies, improved biofuels and efficient methods of capturing carbon dioxide from power plants. It is often credited with injecting enthusiasm into the field. But in the slowmoving industry, its actual impact has been difficult to determine.

At the 2015 Energy Innovation Summit near Washington DC, ARPA-E deputy director Cheryl Martin described how companies that are peddling agency-supported technologies have already invested more than six times the original ARPA-E investment.

"I think we are starting to make a difference," says Martin. "We are tackling global problems and having tangible results."

ARPA-E grants are relatively large - up to $\$ 10$ million over three years - but come with strings. Projects must have ongoing, direct engagement with programme managers, and meet strict performance benchmarks. So far, the agency has cancelled 21 projects, and staff members have worked to redesign others in light of surprising results.

The agency funds academics and small startup companies, but it also supports research by industrial giants such as United Technologies Corporation (UTC) of Hartford, Connecticut, which has led several projects and has been involved in about a dozen others. Company officials say that these projects - which include batteries, advanced manufacturing, refrigeration and natural-gas storage - are in a grey area where the market does not justify private investment in early-stage technology.

"ARPA-E really did create an ecosystem of innovation that did not exist before," says Craig Walker, who oversees energy technology at UTC's research arm. He estimates that perhaps two-thirds of the work funded by ARPA-E over the past six years falls into categories that did not have a home in conventional funding agencies.

That is how ARPA-E was conceived. A 2007 report by the US National Academies proposed an agency to fill a gap between basic and industrial energy research. It called for ARPA-E's budget to build up to around $\$ 1$ billion annually over the course of five or six years, but despite fairly broad bipartisan support, the agency has been stuck at around
\$280 million since 2012.

For Douglas Kirkpatrick, chief executive of technology firm BlackPak of San Francisco, California, the funding situation is not necessarily a bad sign. He says that many investors entered the game a few years ago thinking

"ARPA-E really
did create an
ecosystem of
innovation that
didnot exist
before."
that they could get rich on a hot new energy technology, as with the Internet boom, but energy markets are slow and methodical.

BlackPak is developing a low-pressure natural-gas tank that could loosen petrol's grip on the transportation sector. With that ambitious goal, the project has attracted \$4.6 million in ARPA-E funding, but its first step is decidedly modest: corner the market in golf-course lawnmowers. Cars come later. "You start by chewing on the tail of the elephant," says Kirkpatrick.

He learned that lesson during eight years at DARPA, first as a programme manager and then as chief scientist. DARPA targets its products at the US military rather than golf courses, Kirkpatrick explains, but the same principle applies: you need patience to see whether a technology will spread.

"You've just got to populate the space and then wait." 